\title{
Synaptic Localization and Neural Regulation of an N-Acetylgalactosaminyl Transferase in Skeletal Muscle
}

\author{
Leland J.C. Scott, ${ }^{1}$ Janne Balsamo, ${ }^{2, a}$ Joshua R. Sanes, ${ }^{1}$ and Jack Lilien².a \\ 'Department of Anatomy and Neurobiology, Washington University School of Medicine, St. Louis, Missouri 63110, and \\ 2Department of Zoology, University of Wisconsin, Madison, Wisconsin 53706
}

\begin{abstract}
We have previously documented the properties of a $\sim 220$ $\mathrm{kDa}$ cell surface glycosyltransferase that transfers $\mathrm{N}$-acetylgalactosamine to oligosaccharide chains (Balsamo et al., 1986b). Because $\mathrm{N}$-acetylgalactosamine-terminated carbohydrates are concentrated at the neuromuscular junction (Scott et al., 1988), we assayed skeletal muscle for the presence of the $\mathrm{N}$-acetylgalactosaminyl transferase. Using immunohistochemical methods, we found that the enzyme is localized at neuromuscular junctions on normal adult rat muscle fibers. Biochemical assays confirm that junctional areas are highly enriched in the $\sim 220-\mathrm{kDa}$ immunoreactive species as well as in enzyme activity associated with the $\sim 220-k D a$ species. This restricted distribution is dependent on synaptic integrity, as the enzyme appears extrasynaptically on denervation. These results provide a plausible metabolic basis for the localization of a synapse-specific carbohydrate and demonstrate that the expression of a glycosyltransferase is regulated by synaptic interactions.
\end{abstract}

Recently we used lectins and anticarbohydrate antibodies as histochemical probes to show that $N$-acetylgalactosamine-terminated glycuconjugates are selectively concentrated at the vertebrate neuromuscular junction (Sanes and Cheney, 1982; Scott et al., 1988). Because such oligosaccharide structures might be involved in interneuronal recognition (Rutishauser and Jessel, 1988; Schwarting and Yamamoto, 1988), the transferases that catalyze their synthesis are also of interest to neurobiologists. An $N$-acetylgalactosaminyl transferase characterized in our laboratory has a number of unique properties that make it particularly intriguing in this regard. A major fraction of the enzyme is present at the cell surface (Balsamo and Lilien, 1979, 1982; Balsamo et al., 1986b), where it exists in a stable multimolecular complex (Balsamo and Lilien, 1982) with the calcium-dependent cell-cell adhesion molecule $N$-cadherin (Balsamo and Lilien, 1989). Additionally, it can transfer GalNAc-phosphate to o-serine-, or threonine-linked acceptors in a phosphodiester linkage (Balsamo et al., 1986a).

We have now assayed skeletal muscle for the presence of the GalNAc transferase, reasoning that the distribution of the enzyme could account for the concentration of GalNAc at the

\footnotetext{
Received May 12, 1989; revised June 29, 1989; accepted July 12, 1989.

This work was supported by grants from the MDA (to J.R.S.) and the NIH, EY 05860 (to J.L.).

Correspondence should be addressed to Jack Lilien, Department of Zoology University of Wisconsin, 250 North Mills, Madison, WI 53706.

" Present address: Department of Biological Sciences, Clemson University, Clemson, SC 29631.

Copyright (C) 1990 Society for Neuroscience $0270-6474 / 90 / 010346-05 \$ 02.00 / 0$
}

synapse, and that we might use the neuromuscular junction (NMJ) to learn whether GalNAc transferase expression is regulated by synaptic interactions. We report that the GalNAc transferase is highly concentrated at neuromuscular junctions in normal adult muscle, but appears extrasynaptically following denervation.

\section{Materials and Methods}

Antitransferase antibodies. Three monoclonal antibodies were used in these studies. The first, $6 \mathrm{H} 5$, has already been described (Balsamo et al., 1986b). This antibody is an IgG and recognizes a polypeptide at $220 \mathrm{kDa}, \sim \mathrm{pI} 5.0$, with GalNAc transferase activity. Two additional monoclonal antibodies were prepared using the $\sim 220-\mathrm{kDa}, \mathrm{pI}-5.0$ (see Balsamo et al., 1986b) molecule excised from 2D SDS-PAGE of chick embryo neural retina as immunogen for 1 intrasplenic injection. Two IgMs were recovered, 7A2 and $1 \mathrm{~B} 11$, both of which recognize the $\sim 220$ $\mathrm{kDa}, \mathrm{pI}-5.0$ molecule on immunoblots of 2D SDS-PAGE and precipitate GAINAc transferase activity.

A polyclonal antibody was also prepared using as immunogen the $\sim 220-\mathrm{kDa}, \mathrm{pI}-5.0$ molecule dissected from 2D SDA-PAGE. The initial injection was with antigen in complete Freund's adjuvant; all subsequent injections were in incomplete Freund's. Rabbits were injected on a weekly schedule for 8 weeks, bled, and the serum collected. The serum recognized the $\sim 220-\mathrm{kDa}, \mathrm{pI}-5.0$ molecule on 2D SDS-PAGE of chick neural retina and precipitated GalNAc transferase activity. As this serum also recognized other unidentified molecules, it was affinity-purified on nitrocellulose replicas of the $\sim 220$-kDa transferase (Smith and Fisher, 1984). Figure 1 compares the reactivity of this affinity-purified polyclonal antiserum and the monoclonal antibodies on Western transfers of SDS-PAGE.

Histochemistry. Muscles were cross-sectioned at 4-6 $\mu \mathrm{m}$ on a cryostat and stained as detailed in Scott et al. (1988). For antibody staining, sections were incubated for $2-3 \mathrm{hr}$ with primary antibody diluted in $10 \mathrm{mg} / \mathrm{ml}$ bovine serum albumin in phosphate buffered saline (PBS BSA). The sections were washed in PBS/BSA and then incubated $1 \mathrm{hr}$ with an affinity-purified goat anti-mouse or anti-rabbit antibody containing 5\% rat serum and rhodamine-labeled $\alpha$-bungarotoxin, prepared as described by Ravdin and Axelrod (1977), to show end plates. Finally, sections were mounted in 90\% glycerol in PBS, pH 8, containing $1 \mathrm{mg}$ $\mathrm{ml}$ paraphenylenediamine to limit bleaching. For localization of GalNActerminated glycoconjugates, sections were incubated with biotinylated Vicia villosa B4 isolectin $(2-5 \mu \mathrm{g} / \mathrm{ml})$, washed, and reincubated with fluorescein-streptavidin. All incubations and washes were in PBS.

Enzyme activity measurements. Rat diaphragms were dissected into end-plate-rich regions and end-plate-free regions (Merlie and Sanes, 1985 ) and homogenized in $20 \mathrm{~mm}$ HEPES, $\mathrm{pH} 7.4,0.15 \mathrm{M} \mathrm{NaCl}$ with $1.0 \%$ Triton $\mathrm{X}-100$, and $50 \mu \mathrm{g}$ of each antipain, leupeptin, and chymostatin (HSTI) to inhibit proteases. After $30 \mathrm{~min}$ on ice, the homogenate was centrifuged at $20,000 \times g$ for $30 \mathrm{~min}$. The supernatant was laycred on top of a tubc containing $100 \mu \mathrm{l}$ of $50 \%$ sucrose and $1 \mathrm{ml}$ of $20 \%$ sucrose, both in HSTI, and centrifuged at $100,000 \times \mathrm{g}$ for $90 \mathrm{~min}$. The $20-50 \%$ sucrose interface was collected and assayed. The assay mixture contained $100 \mu$ l of extract, $10 \mathrm{mM} \mathrm{Mn}^{2+}, 1 \mathrm{mM} \mathrm{ATP}$, and 0.23 $\mu_{\mathrm{M}}$ UDP-[ $\left[{ }^{3} \mathrm{H}\right] \mathrm{GalNAc}(\mathrm{NEN}, 8.7 \mathrm{Ci} / \mathrm{mM}$ ), with or without $20 \mathrm{mM}$ EDTA After $60 \mathrm{~min}$ at $37^{\circ} \mathrm{C}, 100 \mu 1$ of $1 \%$ phosphotungstic acid $/ 6 \%$ trichloroacetic acid (PTA/TCA) was added to the incubation mixture. The resultant precipitate was collected on glass fiber filters (Whatman GF/ 


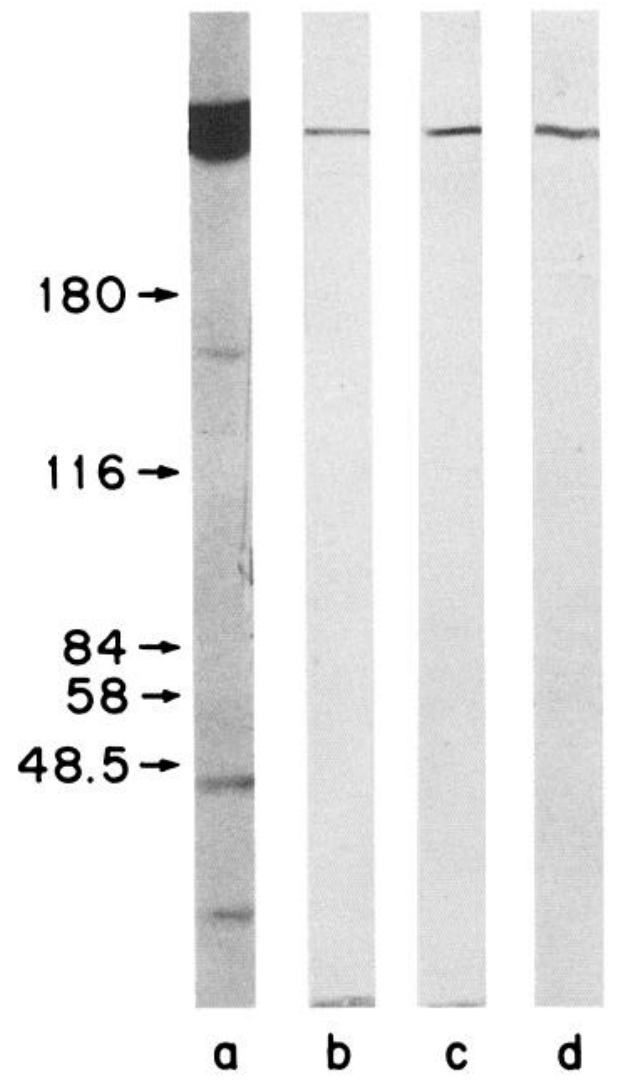

Figure 1. Immunoblot of retina homogenate with monoclonal and affinity-purified polyclonal antitransferase antibodies. $a$, Monoclonal antibody $6 \mathrm{H} 5$ detected with ${ }^{125} \mathrm{I}$ goat anti-mouse Ig. $b$, Monoclonal antibody 1 B 11 detected with alkaline phosphatase-conjugated goat antimouse IgM. $c$, Monoclonal antibody 7A2 detected as in $b . d$, Affinitypurified rabbit antibody detected with alkaline phosphatase conjugated goat anti-rabbit IgG.

F) and counted in a liquid scintillation spectrometer (Balsamo and Lilien, 1979).

Immunoreactivity and enzyme activity on Western transfers. Five 10-d embryonic chick neural retinas were homogenized in $1 \mathrm{ml}$ of $0.15 \mathrm{M}$ $\mathrm{NaCl}, 50 \mathrm{~mm}$ HEPES, pH 7.2, containing 1\% Triton X-100, $100 \mu \mathrm{g}$ DNase and $50 \mu \mathrm{g}$ each antipain, leupeptin, and chymostatin. After 30 min on ice the homogenate was centrifuged at $9000 \times g$ for $5 \mathrm{~min}$ and the supernatant was diluted with an equal volume $2 \times$ SDS sample buffer $(6 \%$ SDS, $10 \% \beta$-mercaptoethanol, $20 \%$ glycerol and $0.25 \mathrm{~m}$ Tris, $\mathrm{pH} 6.8$ ) and used for SDS-PAGE on 7\% gels. Nitrocellulose replicas of the SDS-PAGE were reacted with the monoclonal and polyclonal antibodies followed by the appropriate second antibody (Balsamo et al., 1986b).

Rat diaphragms were dissected into end-plate-rich and end-plate-free regions, homogenized in the above buffer lacking Triton X-100, and centrifuged at $2000 \times g$ for $5 \mathrm{~min}$. The supernatants were centrifuged again at $50,000 \times \mathrm{g}$ for $30 \mathrm{~min}$. Pellets from equal wet weights of tissue were solubilized in $3 \% \mathrm{SDS} / \beta$-mercaptoethanol buffer, processed through SDS-PAGE on $7 \%$ gels, and transferred to nitrocellulose (Balsamo et al., 1986b). Nitrocellulose strips were reacted with monoclonal antibody $1 \mathrm{~B} 11$ followed by [ $\left.{ }^{125} \mathrm{I}\right]-$ goat anti-mouse Ig. To analyze enzyme activity, nitrocellulose blots were cut into $1-\mathrm{cm}$ strips and assayed as described in Balsamo et al. (1986b).

\section{Results}

Immunohistochemical localization of the GalNAc transferase at the NMJ

Monoclonal antibodies have been raised to GalNAC transferase from chick retina, and their specificity demonstrated by immunoblotting homogenates of several tissues, including skeletal
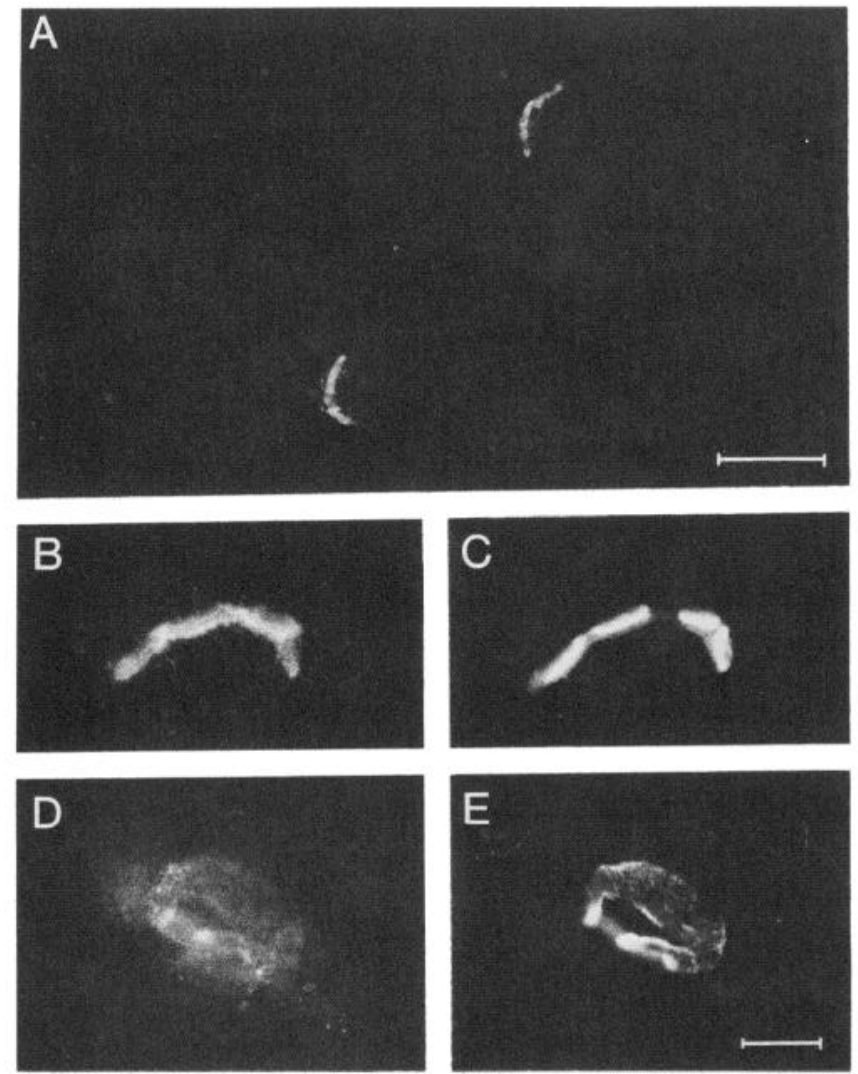

Figure 2. Immunocytochemical evidence that GalNAc transferase is concentrated at the neuromuscular junction. $A, B$, Cross-sections of rat skeletal muscle, stained with monoclonal anti-GalNAc transferase (clone $6 \mathrm{H5}$ ) and fluorescein-conjugated goat anti-mouse $\mathrm{IgG}$. $C$, Same field as $B$, counterstained with rhodamine- $\alpha$-bungarotoxin, to show that GalNAc transferase-rich areas are acetylcholine receptor-rich synaptic sites; extrasynaptic portions of the muscle fiber surface bear no detectable GalNAc transferase. $D, E, E n$ face view of an end plate from a flexor digitorum superficialis muscle that was stained with anti-GalNAc transferase $(D)$ and rhodamine-bungarotoxin $(E)$ while alive; the muscle was then fixed and single fibers were teased and mounted. GalNAc transferase is exposed on an extracellular surface at the neuromuscular junction. $B-E$ are at the same magnification, but the end plate in $B$ and $C$ is larger because it is from a $200-\mathrm{gm}$ rat whereas that in $D$ and $E$ is from a $60-\mathrm{gm}$ rat. Scale bar, $20 \mu \mathrm{m}$ in $A, ; 10 \mu$ in $E$.

muscle (Balsamo et al., 1986b, and Fig. 1). To localize the GalNAc transferase, we stained sections of adult chicken and rat muscle with anti-GalNAc transferase antibodies and fluorescein-second antibody. In both chicken (not shown) and rat, immunoreactivity was restricted to small patches on the muscle fiber surface (Fig. 2, $A, B$ ). These patches were identifiable as synaptic sites by counterstaining with rhodamine- $\alpha$-bungarotoxin (Fig. 2C), a protein that binds tightly and specifically to acetylcholine receptors concentrated in the postsynaptic membrane. Extrasynaptic portions of the muscle fiber surface, muscle cytoplasm, and intramuscular structures such as nerves and blood vessels stained weakly or not at all. Similar or identical patterns of immunoreactivity were obtained with 3 different antitransferase monoclonal antibodies and an affinity-purified polyclonal antibody, indicating considerable similarity between the synaptic immunoreactive material and authentic GalNAc transferase.

The results presented thus far do not distinguish between preand postsynaptic or between intra- and extracellular sites of 


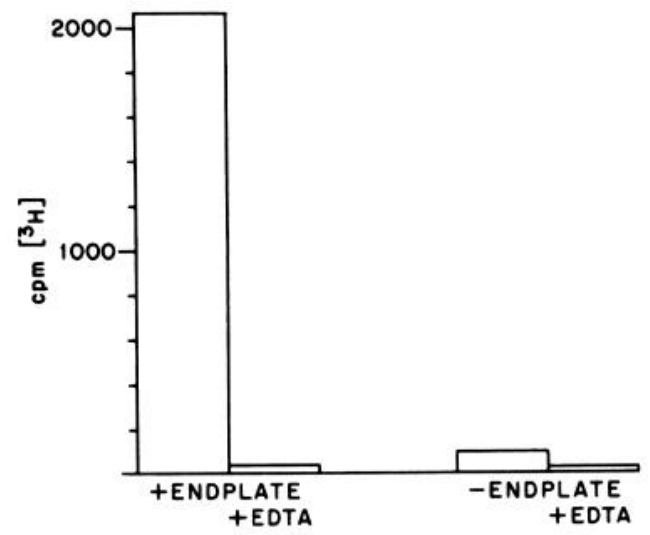

Figure 3. Biochemical evidence that GalNAc transferase is concentrated near synapses. End-plate-rich and end-plate-free regions of rat diaphragm muscle were assayed for total GalNAc transferase activity. Since activity requires $\mathrm{MnCl}_{2}$, control tubes containing $5 \mathrm{~mm}$ EGTA were used to determine background levels.

GalNac transferase. We addressed these issues immunohistochemically. Rat muscles that had been denervated $2 \mathrm{~d}$ earlier to induce degeneration of the motor nerve terminal without altering the distribution of postsynaptic elements were selectively stained at synaptic sites by anti-GalNAc transferase antibody (not shown). This rules out a predominant association of the GalNAc transferase with the nerve terminal. Similar staining was observed when live muscles were incubated with antibody, demonstrating that at least some epitopes of the GalNAc transferase are external to the plasma membrane (Fig. 2, D, E). Thus, GalNAc transferase is highly concentrated in or near the external surface of the postsynaptic membrane at the NMJ.
Immunohistochemical observations also indicate that the binding of antibodies to 2 other glycosyltransferases is not confined to synaptic areas. Antibodies to a galactosyltransferase purified from liver (Urich et al., 1986) and a sialyltransferase purified from kidney (Roth et al., 1985) stain discrete structures in both synaptic and extrasynaptic regions of muscle fibers (not shown). This staining coincides with a histochemical reaction for thiamine pyrophosphorylase (Novikoff and Goldfischer, 1961), conventionally used to mark the transferase-rich Golgi apparatus. Thus, the histochemical results shown in Figure 2 do not reveal a general concentration of glycosyltransferases at the postsynaptic apparatus of the adult NMJ.

\section{Biochemical localization of the GalNAc transferase at the NMJ}

To determine whether the immunohistochemical observations reflect the presence of authentic GalNAc transferase in junctional, but not extrajunctional, regions, such areas were dissected from rat diaphragm and examined biochemically. Enzymatic assays performed on homogenates of muscle show 1020-fold higher specific activity per unit protein in synapse-rich compared to synapse-free samples (Fig. 3). Immunoblotting reveals $\sim 220$-kDa molecule in synapse-rich but not in synapsefree regions of the muscle (Fig. 4, top). The mobility of this band is indistinguishable from the chick retina enzyme (see Balsamo et al., 1986b, and Fig. 1). As this GalNAc transferase has the ability to retain its catalytic activity following SDSPAGE and transfer to nitrocellulose (Balsamo et al., 1986b), we were able to assay strips from the nitrocellulose replicas to determine whether activity was coincident with immunoreactivity. Indeed, as shown in the data in Figure 4, bottom, activity is coincident with the $\sim 220-\mathrm{kDa}$ immunoreactive band. Fur-
Figure 4. Western blots of SDS-PAGE show coincident immunoreactivity and enzyme activity. Top, Western blotting with monoclonal anti-Ga1NAc transferase (clone 1B11) and ${ }^{125}$ I-goat antimouse Ig. The lane containing junctional areas revealed a band of $\sim 220$ $\mathrm{kDa}$ that was at least 10 -fold more abundant than in synapse-free samples. Bottom, Western blots run in parallel to that shown at the top were assayed for activity. Activity is coincident with the $\sim 220-\mathrm{kDa}$ immunoreactive band and is greater in synapse-rich (filled circles, solid line) than in synapse-free (filled triangles, dashed line) samples.
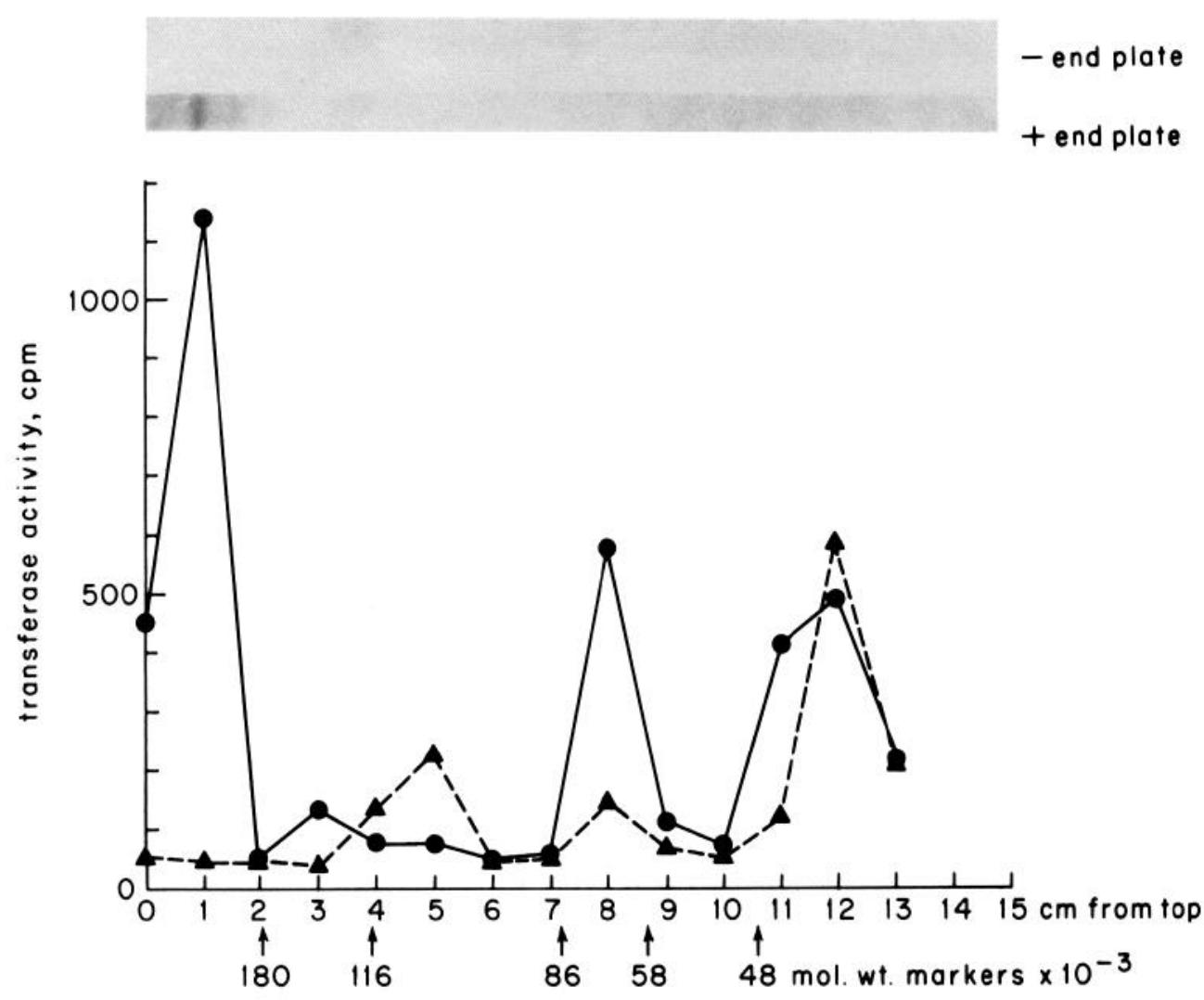
thermore, activity is absent from this position in the synapsefree lane.

\section{Changes in distribution of the GalNAc transferase on denervation}

Several proteins, including acetylcholine receptors (Fambrough, 1979) and the neural cell adhesion molecule, N-CAM (Covault and Sanes, 1985), are concentrated at synaptic sites in normal adult muscle, but appear extrasynaptically within $3 \mathrm{~d}$ following denervation. We have observed that the GalNAc-terminated glycoconjugates also appear extrasynaptically following denervation (Fig. 5, $A, B$, and Scott, 1988), raising the possibility that the GalNAc transferase might behave similarly.

To test this idea, we stained denervated muscle with the antiGalNAc transferase antibody and found that the enzyme does appear on extrasynaptic as well as synaptic portions of the denervated muscle fiber surface (Fig. 5, $C, D$ ). Extrasynaptic GalNAc transferase becomes detectable between 3 and $7 \mathrm{~d}$ after denervation, and remains at a relatively constant level for at least 8 weeks if denervation is maintained. Each of the antibodies, 3 monoclonal and 1 polyclonal, gave the same result. Additionally, enzymatic assays of the synapse-free region at 10 $\mathrm{d}$ following denervation showed an increase in specific activity of greater than 20-fold (data not shown). In contrast, the distribution of neither the galactosyl transferase (Urich et al., 1986) nor the sialyl transferase (Roth et al., 1985) was detectably altered by denervation. Previous assays of galactosyl and sialyl transferase activity in muscle have also shown only small changes in activity (2-fold or less) following denervation (Leung et al., 1986). Thus, the levels and distribution of the GalNAc transferase are neurally regulated in muscle, such that the enzyme and the GalNAc-terminated glycoconjugates both appear in extrasynaptic areas following denervation.

\section{Discussion}

Our conclusion that the GalNAc transferase is localized at the adult NMJ is based on both histochemical observations and biochemical assays. Both monoclonal and polyclonal antibodies which recognize the $\sim 220-\mathrm{kDa}$ transferase molecule reveal that the distribution of the GalNAc transferase is similar to that of acetylcholine receptors. Two other glycosyltransferases, a galactosyl and a sialyltransferase, are not found at the NMJ, excluding the possibility that glycosyltransferases in general are concentrated at the NMJ.

For biochemical assays, the unique morphology of the rat diaphragm muscle, in which the junctional region is restricted to a semicircular band, makes it easy to dissect areas of muscle that are rich in junctions and areas void of junctions. Direct assays for GalNAc transferase in each of these areas reveal the presence of enzyme activity in junctional but not extrajunctional areas. Additionally, the $\sim 220-\mathrm{kDa}$ immunoreactive molecule is present on nitrocellulose replicas from SDS-PAGE of junctional, but not extrajunctional, areas and GalNAc transferase activity is coincident with the position of $\sim 220-\mathrm{kDa}$ molecule on the nitrocellulose replicas.

Like a number of other molecules localized at the NMJ, the distribution of the GalNAc transferase is regulated by synaptic integrity. Following denervation, the enzyme becomes histochemically detectable extrajunctionally within $3 \mathrm{~d}$ and at $10 \mathrm{~d}$ shows a large increase in extrajunctional activity. The extrajunctional appearance of the enzyme parallels the extrajunctional appearance of the GalNAc-containing glycoconjugates.
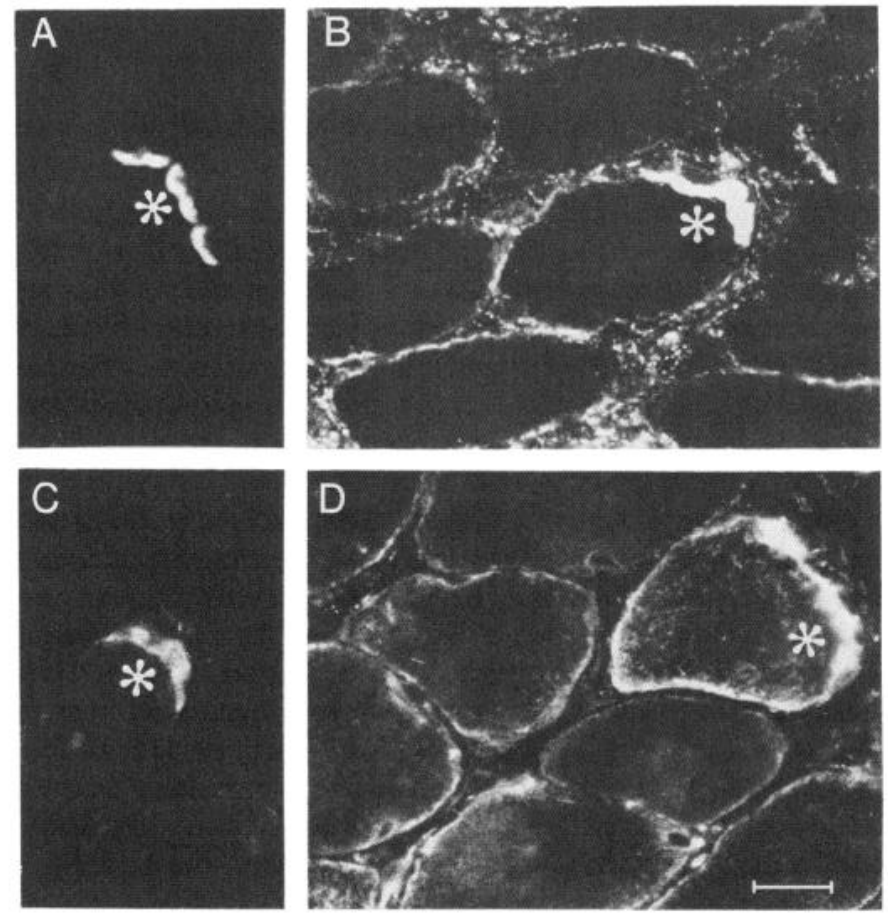

Figure 5. Appearance of Ga1 NAc transferase and Ga1NAc-terminated glycoconjugates in extrasynaptic areas following denervation of adult muscles. Sections of normal $(A, C)$ or 10-d denervated $(B, D)$ rat diaphragm were stained with the biotinylated lectin VVA-B4 plus fluorescein-streptavidin $(A, B)$ or with monoclonal anti-GalNAc transferase plus fluorescein goat anti-mouse $\operatorname{Ig}(C, D)$. VVA-B4 and Anti-Ga 1NAc transferase stain muscle fiber surfaces and some intracellular material, as well as end plates, in denervated muscle. Positions of synaptic sites, identified by counterstaining with rhodamine- $\alpha$-bungarotoxin, are marked by asterisks. Scale bar, $20 \mu \mathrm{m}$.

Thus, the levels and distribution of the GalNAc transferase are neurally regulated in muscle.

The coincidence of GalNAc-terminated glycoconjugates and the GalNAc transferase at the adult NMJ and following denervation suggests that this transferase may be responsible for addition of the GalNAc residues. However, the GalNAc-containing molecules at the NMJ include both glycoproteins ( 1 of which is the tailed form of acetylcholinesterase) and glycolipids (Scott et al., 1988; see also Kaupmann and Jockusch, 1988), and it is known that separate GalNAc transferases with narrow specificities transfer GalNAc to different acceptors (Beyer et al., 1981; Conzelmann and Kornfeld, 1984; Das et al., 1986; Takeya et al., 1987; Yanagisawa et al., 1987). It is therefore possible that several different transferases synthesize the GalNAc-containing molecules at the NMJ.

The selective accumulation of GalNAc-terminated glycoconjugates at the NMJ could arise in any of 3 ways: These glycoconjugates might be preferentially synthesized in the synaptic areas, they might be synthesized throughout the muscle and targeted or trapped at the synapse, or they might be contributed by enzymes provided by the nerve terminal. The result that the GalNAc transferase is concentrated in or near the postsynaptic membrane supports the first of these alternatives. The observation that GalNAc transferase and GalNAc-terminated glycoconjugates appear together in extrasynaptic areas following denervation is also consistent with the idea that these glycoconjugates are deposited near their sites of synthesis. However, 
it remains to be shown directly whether the GalNAc transferase we have measured does, in fact, synthesize any or all of the GalNAc-terminated glycoconjugates at the NMJ.

In summary, our results provide a plausible explanation for the synapse-specific localization of the GalNAc-terminated glycoconjugates. They also raise the intriguing possibility that the transferase might modulate or mediate adhesive interactions at the junction through its control of glycoconjugate synthesis or, more directly, through adhesive interactions with other molecules. Our recent observation that $N$-cadherin, a calcium-dependent adhesion molecule, is localized to the junctional area (L. Scott, J. Balsamo, J. Lilien, J. Sanes, unpublished observations) and that the transferase is associated with and can glycosylate $N$-cadherin (Balsamo and Lilien, 1989) makes this suggestion even more tempting.

\section{References}

Balsamo, J., and J. Lilien (1979) Properties of $\beta$ - $N$-acetylgalactosaminyl transferase and its mobilization from an endogenous pool to the cell surface of embryonic chick neural retina. Biochemistry 19: 24792484.

Balsamo, J., and J. Lilien (1982) An $N$-acetylgalactosaminyltransferase and its acceptor in embryonic chick neural retina exist in interconvertible particulate forms depending on their cellular location. J. Biol. Chem. 10: 349-354.

Balsamo, J., and J. Lilien (1989) $N$-cadherin is stably associated with, and is an acceptor for a cell surface $N$-acetylgalactosaminyl transferase. J. Biol. Chem. (in press).

Balsamo, J., R. S. Pratt, and J. Lilien (1986a) Chick neural retina $N$-acetylgalactosaminyltransferase/acceptor complex: Catalysis involves transfer of $\mathrm{N}$-acetylgalactosamine phosphate to endogenous acceptors. Biochemistry 19:5402-5407.

Balsamo, J., R. S. Pratt, M. R. Emmerling, G. B. Grunwald, and J. Lilien (1986b) Identification of the chick neural retina cell surface $\mathrm{N}$-acetylgalactosaminyltransferase using monoclonal antibodies. J. Cell. Biochem. 32: 125-141.

Beyer, T. A., J. E. Sadler, J. I. Rearick, J. C. Paulson, and R. T. Hill (1981) Glycosyltransferases and their use in assessing oligosaccharide structure and structure-function relationships. Adv. Enzymol. 52:2375.

Conzelmann, A., and S. Kornfeld (1984) A murine cytotoxic T lymphocyte cell line resistant to Vicia villosa lectin is deficient in UDPGalNAc: $\beta$-Galactose $\beta 1,4-N$-acetylgalactosaminyltransferase. J. Cell Biol. 259: 12536-12542.

Covault, J., and J. R. Sanes (1985) Neural cell adhesion molecule (NCAM) accumulates in denervated and paralyzed skeletal muscle. Proc. Natl. Acad. Sci. USA 82: 4544-4528.

Das, K. K., M. Basu, and S. Basu (1986) Biosynthesis in vitro of a globoside containing a 2-acetamido-2-deoxy- $\beta$-D-galactopyranosyl group (1-3)-linked and forssman glycolipid by two $N$-acetylgalacto- saminyltransferases from chemically transformed guinea pig cells. Carbohydrate Res. 149: 119-135.

Fambrough, D. M. (1979) Control of acetylcholine receptors in skeletal muscle. Physiol. Rev. 59: 165-227.

Kaupmann, K., and H. Jockusch (1988) Dolichos biflorus agglutinin receptors in mouse muscle. II. Biochemical properties in relation to molecular forms of acetylcholinesterase. Eur. J. Cell Biol. 46: 419424.

Leung, W. N., P. L. Jeffrey, and J. A. P. Rostas (1986) Effect of denervation on sarcolemmal proteins and glycoproteins of fast and slow mammalian skeletal muscle. Exp. Neurol. 91: 229-245.

Merlie, J. P., and J. R. Sanes (1985) Concentration of acetylcholine receptor mRNA in synaptic regions of adult muscle fibres. Nature 317: $66-68$.

Novikoff, A. B., and S. Goldfischer (1961) Nucleoside diphosphatase activity in the Golgi apparatus and its usefulness for cytological studies. Biochemistry 47: 802-810.

Ravdin, P., and D. Axelrod (1977) Fluorescent tetramethyl rhodamine derivatives of $\alpha$-bungarotoxin: Preparation, separation, and characterization. Anal. Biochem. 80: 585-592.

Roth, J., D. J. Taatjes, J. M. Lucocq, J. Weinstein, and J. C. Paulson (1985) Demonstration of an extensive trans-tubular network continuous with the Golgi apparatus suggesting that it might function in glycosylation. Cell 43: 287-295.

Rutishauser, U., and T. M. Jessel (1988) Cell adhesion molecules in vertebrate neural development. Physiol. Rev. 68: 819-857.

Sanes, J. R., and J. M. Cheney (1982) Lectin binding reveals a synapsespecific carbohydrate in skeletal muscle. Nature 300:646-647.

Schwarting, G. A., and M. Yamamoto (1988) Expression of Glycoconjugates during development of the vertebrate nervous system. BioEssays 9: 19-23.

Scott, L. J. C. (1988) Identification and Characterization of a Synapse Specific Carbohydrate Structure at the Neuromuscular Junction. Ph. D. Dissertation, Washington University, St. Louis, MO.

Scott, L. J. C., F. Bacou, and J. R. Sanes (1988) A synapse-specific carbohydrate at the neuromuscular junction: Association with both acetylcholinesterase and a glycolipid. J. Neurosci. 8: 932-944.

Smith, D. E., and P. A. Fisher (1984) Identification, developmental regulation, and response to heat shock of two antigenically related forms of a major nuclear envelope protein in Drosophila embryos: Application of an improved method for affinity purification of antibodies using polypeptides immobilized on nitrocellulose blotts. J. Cell Biol. 99: 20-28.

Takeya, A., O. Hosomi, and T. J. Kogure (1987) Identification and characterization of UDP-GalNAc: Neu.Ac. $\alpha$ 2-3 Gal $\beta$ 1-4 Glc(NAc) $\beta$ 1-4 [GalNAc 2 Gal] $N$-acetylgalactosaminyl transferase in human blood plasma. J. Biochem. (Tokyo) 101: 251-259.

Urich, J. T., J. R. Schenck, H. G. Rittenhouse, N. L. Shaper, and J. H. Shaper (1986) Monoclonal antibodies to bovine UDP-galactosyltransferase. J. Biol. Chem. 261: 7975-7981.

Yanagisawa, K, N. Taniguchi, and A. Makita (1987) Purification and properties of GM2 synthase, UDP- $N$-acetylgalactosamine: GM2 $\beta-N$ acetylgalactosaminyltransferase from rat liver. Biochim. Biophysic. Acta 919: 213-220. 